Interação em Psicologia, 2007, 11(1), p. 27-42

\title{
Produção e compreensão do texto escrito: Um estudo junto a surdos universitários ${ }^{1}$
}

\author{
Maria Helena Fávero \\ Meireluce Leite Pimenta \\ Márcia Rangel Pacifici \\ Universidade de Brasília
}

\begin{abstract}
RESUMO
Em Fávero e Pimenta (2006), apontou-se que a dificuldade dos surdos na compreensão de problemas escritos de matemática relaciona-se ao uso inadequado da LIBRAS pelos profissionais da instituição escolar, como instrumento para a organização de significados semióticos e aquisição de conhecimentos. Com o intuito de estudar o significado das irregularidades apontadas na literatura a respeito da produção escrita dos surdos, analisamos a produção de 6 surdos escolarizados, 5 universitários e 1 secundarista, entre 17 e 29 anos, 4 do sexo masculino e 2 do feminino, em resposta a um protocolo sobre a sua compreensão de um texto jornalístico e sobre sua concepção a respeito de suas competências e dificuldades no que diz respeito à produção e compreensão textual. Evidenciou-se que: os participantes desvalorizam suas próprias competências de produção e compreensão textual; apresentam uma adequada compreensão do texto; utilizam o processamento visual na escrita. Reitera-se a defesa da língua de sinais como língua materna dos surdos e a necessidade de se considerar o processamento visual e o desenvolvimento da consciência sintática e morfossintática, na aquisição da segunda língua. Para tanto, defende-se a importância da pesquisa, tendo por método de investigação, o próprio procedimento de intervenção psicopedagógica, o que significa considerar a atividade mediada.
\end{abstract}

Palavras-chave: compreensão textual; produção escrita; processamento visual; surdo.

\begin{abstract}
Production and comprehension of written texts: A study of deaf university students

Fávero and Pimenta (2006) demonstrated that the difficulties that deaf individuals experience in comprehending written mathematical problems is related to teaching professionals inadequate use of Brazilian Sign Language (LIBRAS) as an instrument for knowledge acquisition and for the organisation of symbolic meaning. In order to understand the irregularities observed in the literature regarding written production by deaf individuals, research was carried out involving six deaf subjects aged between 17 and 29 (four male and two female), of which five were college students and one was in secondary school. Subjects responded to a series of questions regarding comprehension of a newspaper article and evaluation of their own strengths and weaknesses in relation to textual production and comprehension. It was found that the subjects undervalued their textual production and comprehension skills, showed adequate textual comprehension and used visual processing in writing. Thus, the defence of sign language as the native language of deaf individuals is reiterated as is the need to take into account both visual processing and the development of syntactic and morphosyntactic awareness in the acquisition of a second language. We advocate further research which takes mediated activity into account, adopting the psycho-pedagogical intervention itself as the study method.
\end{abstract}

Keywords: textual comprehension; written production; visual processing; deaf person.

Existe um consenso no discurso do meio escolar institucional, assim como nos relatos de pesquisa, tanto nacionais como internacionais, de que o surdo apresenta dificuldades na aquisição da língua convencional, seja na escrita como na compreensão textual (cf. Flaherty \& Moran, 2004; Góes, 1996; Harris \& Moreno, 2004; Marschark, Mouradian \& Halas, 1994; 
Mayer \& Akamatsu, 2000; Perfetti \& Sandak, 2000). Historicamente, este consenso fundamentou um outro: aquele segundo o qual a aquisição da língua oral, a chamada tese da oralização, seria a solução ideal, ou mesmo a única viável para a superação desta dificuldade e a conseqüente superação da deficiência, o que, por sua vez, garantiria a inclusão social do surdo.

No entanto, como salientado por Ferreira-Brito (1997), Quadros (1997), Skliar (1998) e Virole (2002) a tese da oralização não tem se sustentado nas pesquisas das duas últimas décadas e vem sendo substituída, cada vez com mais ênfase, pela tese de que a língua de sinais é, ao contrário do que era apregoado, tão complexa na mediação de significados quanto a língua oral. Uma das implicações desta tese é a defesa da língua de sinais como a língua materna dos surdos (Capovilla, Capovilla \& Suiter, 2004; Evans, 2004; Felipe, 1987; Fernandes, 1989; Gaustad, 2000; Góes, 1996; Meirelles \& Spinillo, 2004; Singleton, Supalla, Litchfied \& Schley, 1998; Zaitseva, Pursglove \& Gregory, 1999; entre outros). Neste caso, podemos dizer que, do ponto de vista da construção do conhecimento, a língua de sinais assume a função de instrumento de mediação para a aquisição da segunda língua, como foi evidenciado em estudo sobre a compreensão e a resolução de problemas escritos de matemática por surdos (Fávero \& Pimenta, 2006).

Por outro lado, as pesquisas sobre a produção escrita do surdo continuam a apontar as diferenças na aquisição da língua convencional em comparação com os ouvintes. Tanto nos estudos em língua inglesa, como naqueles sobre a aquisição do português escrito, os autores salientam as chamadas "construções atípicas” do surdo, entendidas como a desconsideração da ordem convencional da língua portuguesa, a utilização de substantivos substituindo verbos, as limitações do ponto de vista lexical, a impropriedade no uso de preposições e emprego de advérbios, a inadequação da flexão verbal, a limitação na construção de períodos compostos por coordenação e subordinação, a incoerência na coesão do registro discursivo, as dificuldades com a multiplicidade de significados, de similaridades, de metáforas, de expressões idiomáticas, de provérbios, entre outras.

Consensualmente, estas construções atípicas, do ponto de vista da norma culta da língua escrita, comprometem de forma significativa a produção textual do surdo, como apontado por Gesueli (1988), Fernandes (1989), Marschark, Mouradian e Halas (1994), Góes (1996), Cline (1997), Silva (1999), Lang e Albertini
(2001), Meirelles e Spinillo (2004), Gesueli e Moura (2006), Peixoto (2006), entre outros.

A hipótese defendida por Fávero e Pimenta (2006) é que tais construções atípicas referem-se ao uso inadequado da língua de sinais, como instrumento para a organização de significados semióticos e aquisição de conhecimentos, por parte dos profissionais que atuam junto aos surdos na instituição escolar. Desta forma, as referidas construções atípicas seriam fruto de uma prática de alfabetização junto ao surdo que, ainda hoje, negligencia o status da língua de sinais como instrumento semiótico e utiliza com as crianças, adolescentes e adultos surdos um processo similar de alfabetização àquele utilizado junto aos sujeitos ouvintes, cuja língua materna, aqui no Brasil, é o português.

Um ponto a favor desta hipótese é a afirmação de Meireles e Correa (2005), segundo a qual, a língua portuguesa é um sistema alfabético de escrita, no qual, os sons da fala são representados por símbolos gráficos, sem que tal associação grafonêmica garanta a escrita correta. O que estes autores enfatizam é que a ortografia da língua portuguesa nem sempre possui uma regularidade em sua construção, de modo que a escrita correta dependerá, portanto, do domínio tanto das normas ortográficas regulares quanto das construções irregulares. Para sustentar sua tese, os autores citam o estudo de Rego e Buarque (1997) sobre a aquisição da ortografia da língua portuguesa por sujeitos ouvintes. Estes autores examinaram a influência da consciência fonológica - entendida como capacidade de refletir e manipular intencionalmente as unidades sonoras das palavras - e a influência sintático-semântica - entendida como a habilidade de reflexão e manipulação intencional das estruturas gramaticais e dos significados das sentenças, na referida aquisição. Os resultados obtidos por Rego e Buarque (1997) indicam que o conhecimento sobre os morfemas indicadores de tempo (passado, presente e futuro, por exemplo) poderia ser facilitado pela consciência sintática e não necessariamente pela consciência fonológica. Assim, podemos dizer que a consciência sintática e a consciência fonológica estão relacionadas com competências particulares.

Outro ponto a favor da nossa hipótese vem da afirmação de Mayer e Akamatsu (2000) de que a dificuldade que o surdo apresenta na atividade de escrita é infinitamente maior do que a atividade de leitura. Ora, este fato nos instiga a pensar que o grande desafio está na utilização das possibilidades morfossintáticas da língua escrita, que, aliás, são infinitas, ou seja, na construção de possibilidades de generalizações. 
Portanto, diante do exposto, podemos tecer algumas considerações. Em primeiro lugar, a identificação de construções atípicas, na escrita dos surdos, sempre se dá em referência à norma canônica da língua portuguesa. Assim, quando consideramos a estrutura da língua brasileira de sinais, a LIBRAS, podemos entender as inadequações associadas à estrutura sintática, apontadas pela literatura, como indícios de inconsistências no desenvolvimento da consciência sintática e morfossintática da língua portuguesa. Em segundo lugar, se a consciência fonológica não ajuda os surdos a escrever corretamente segundo a estrutura da língua portuguesa, ou seja, não fundamenta a construção da consciência sintática, então os treinos de regras ortográficas tão utilizadas na escolarização em geral e, em especial na escolarização dos surdos, poderiam quando muito, levar à escrita correta de palavras.

Em terceiro lugar, uma vez que as pesquisas têm evidenciado que os surdos apresentam um bom desempenho ortográfico, e que isso acontece independente das regularidades e irregularidades ortográficas das palavras, então significa que o surdo não utiliza a consciência fonológica no processo de decodificação destas, mas sim uma consciência visual da morfologia das palavras.

Por fim, se a consciência morfossintática e sintática não estão necessariamente, associadas à consciência fonológica, isto é, não são intrinsecamente dependentes da associação entre o som e o símbolo gráfico considerado como uma barreira para o surdo no processo de aquisição de uma língua escrita - então, teoricamente, o surdo poderia desenvolver a consciência sintática e morfossintática da língua por um processo de decodificação visual.

Resta, portanto, uma questão teórica e metodológica importante a ser respondida: como favorecer o desenvolvimento da consciência sintática e morfossintática da língua escrita no surdo e como mediar as diferentes áreas do conhecimento tomando por base o processamento viso-espacial?

Optamos por começar a procurar uma resposta, na análise da produção escrita de surdos com uma história de escolarização longa e de sucesso, com o intuito de obter pistas sobre as características desta produção em termos da filiação entre competências e dificuldades, como proposto por Fávero (2003) e, além disto, identificar a concepção dos surdos sobre suas próprias competências e dificuldades em relação à produção escrita e à compreensão textual.

Usaremos a terminologia disacusia neurossensorial para nos referirmos a um distúrbio na audição, expresso em qualidade e não em intensidade sonora que se origina no ouvido interno, ou no nervo auditivo; bilateral caso a perda auditiva ocorra em ambos ouvidos, direito e esquerdo; pré-lingual para a surdez que ocorreu desde o nascimento ou em período anterior ao desenvolvimento da fala, e pós-lingual, à surdez que ocorreu em período posterior à aquisição espontânea da fala. Considera-se normal a pessoa com perda auditiva entre 0 a 15 decibéis. A partir disto, já existe um comprometimento da audição, o que se denomina de surdez leve variando entre 16 a $40 \mathrm{~dB}$ A surdez severa corresponde a uma perda entre 70-90 dB, e a surdez profunda corresponde a perda acima de $90 \mathrm{~dB}$ (Madalena, 1997; Rinaldi, 1997).

\section{MÉTODO}

\section{Participantes}

Participaram desse estudo, 6 surdos, 4 do sexo masculino e 2 do feminino, entre 17 e 29 anos, 5 estudantes universitários e 1 estudante do ensino médio, que a partir de agora serão identificados pela inicial maiúscula de seus nomes. Os participantes $\mathrm{M}, \mathrm{R}, \mathrm{C}$, CA, do sexo masculino, são portadores de disacusia neurossensorial bilateral profunda, pré-lingual. Os participantes M e C são estudantes no curso de Sistema de Informações, o participante CA é estudante do curso de Pedagogia e o participante R, cursa o segundo ano do ensino médio. MN, do sexo feminino, apresenta disacusia neurossensorial bilateral profunda, pré-lingual, e é estudante do curso de Análise de Sistemas. O participante $\mathrm{S}$, também do sexo feminino, apresenta disacusia neurossensorial severa à direita $\mathrm{e}$ disacusia neurossensorial profunda à esquerda, prélingual, e é estudante do curso de Arquitetura e Urbanismo.

\section{Procedimento}

Optamos por utilizar um texto que, embora publicado em jornal, exigisse do leitor o domínio da noção de tempo e espaço e um conhecimento geral sobre conceitos vinculados à matemática, à filosofia, à astronomia, à física e à mitologia. Trata-se do texto intitulado Três visionários cósmicos, de Marcelo Gleiser, publicado na Folha de S. Paulo em 13 de abril de 2003, no Caderno Mais. O texto aborda a questão da construção do conhecimento científico, descrevendo os diferentes paradigmas propostos em diferentes épocas para explicar o funcionamento do universo. A linguagem empregada é construída na modalidade 
escrita padrão, com sintaxe complexa, predomínio de estruturas subordinadas, emprego de vocabulário técnico-científico e expressões conotativas (cf. Anexo A).

Os participantes foram convidados a participar do estudo, por meio de contato individual, ocasião na qual se expunha o objetivo do mesmo. Após a sua anuência, por meio de documento escrito, eles foram convidados a se instalar numa das salas de um instituto para surdos, situado no Plano Piloto de Brasília, $\mathrm{DF}$, onde cada um recebeu uma cópia do texto Três visionários cósmicos e um protocolo contendo questões escritas de duas naturezas: sobre o conteúdo do texto e sobre a sua concepção a respeito de sua própria competência para realizar a atividade proposta (cf. Anexo B). Embora o texto não seja caracterizado eminentemente como argumentativo, os participantes foram instigados, por meio do protocolo, a pensar sobre as duas idéias centrais que o autor desenvolve: 0 fato de o sol ser o centro do sistema solar como uma questão óbvia para uma pessoa do século 21; a explicação do funcionamento do sistema solar como uma questão não tão óbvia.

As instruções foram dadas ao grupo por meio da LIBRAS, salientando que: (a) as respostas ao protocolo deveriam ser elaboradas por escrito; (b) nenhuma informação sobre o conteúdo do texto seria fornecida em LIBRAS aos participantes.

De posse dos protocolos procedemos à análise das respostas tomando-as como discurso e extraindo suas proposições, como proposto por Fávero e Trajano (1998), considerando que a proposição é “o resultado da articulação do sentido, tomado na sua forma mais complexa e menos explícita, com a estrutura lingüística, tomada na sua forma menos complexa e mais explícita” (p. 231). Portanto, assumindo a abordagem da semiótica da cultura, podemos eleger a proposição como uma unidade de análise.

Foram então construídas duas tabelas para cada participante, uma referente à análise do conteúdo e análise gramatical da sua produção escrita e a outra, referente à identificação das suas competências e dificuldades do ponto de vista da produção textual. A análise gramatical e sintática das respostas dos participantes foram elaboradas por uma professora de português e mestre em lingüística que, ao proceder a tais análises, não tinha conhecimento de que se tratava de uma produção escrita por surdos. A análise gramatical e semântica do texto utilizado também foi por ela elaborada.

A título de exemplo, apresentamos as Tabelas 1 e 2 referentes a um dos participantes.

TABELA 1

Análise do Conteúdo e Análise Gramatical e Sintática da Produção Escrita do Participante M

\begin{tabular}{|c|c|c|c|}
\hline Perguntas & Respostas & Proposições & Análise gramatical \\
\hline $\begin{array}{l}\text { 1) Qual o assunto tratado } \\
\text { no texto? }\end{array}$ & $\begin{array}{l}\text { "Os planetas e o sistema } \\
\text { solar" }\end{array}$ & $\begin{array}{l}\text { - O texto fala dos planetas } \\
\text { e do sistema solar }\end{array}$ & $\begin{array}{l}\text { O participante M demonstra pleno domínio do nível fonológi- } \\
\text { co da língua, tanto no que diz respeito à combinação dos } \\
\text { fonemas da língua quanto ao sistema silábico. Não há troca } \\
\text { de fonemas e os padrões silábicos da língua são respeitados. } \\
\text { O participante demonstra também dominar perfeitamente o } \\
\text { sistema ortográfico da língua, desde o emprego das letras } \\
\text { que representam graficamente os sons da língua até o uso } \\
\text { das convenções da escrita, como emprego de maiúsculas e } \\
\text { minúsculas. O participante apresenta pleno domínio do nível } \\
\text { morfossintático da língua: emprega adequadamente o mor- } \\
\text { fema flexional de número, tanto no artigo quanto no substan- } \\
\text { tivo, aplicando o princípio da concordância nominal. A res- } \\
\text { posta dada obedece às normas de construção frasal: o } \\
\text { participante utiliza adequadamente o elemento de coesão (a } \\
\text { conjunção aditiva "e") para ligar os sintagmas nominais que } \\
\text { compõem sua resposta, que guarda coerência com a per- } \\
\text { gunta feita. }\end{array}$ \\
\hline
\end{tabular}




\begin{tabular}{lll}
\hline Perguntas & Respostas & Proposições \\
\hline 2) Na sua opinião, & "Porque o autor escreveu & - O autor escreveu sobre o \\
por que o autor & sobre o tema que ele & tema que acredita. \\
nomeou o texto de & acredita as pesquisas dos & - O autor acredita nas pesqui- \\
três visionários & cientistas que estudam & sas dos cientistas. \\
cósmicos? & sobre rotação entre os & - Os cientistas estudam sobre \\
& planetas e o sistema solar". & a rotação dos planetas. \\
& & - Os cientistas estudam sobre \\
& & o sistema solar.
\end{tabular}

Análise gramatical

O participante $\mathrm{M}$ demonstra pleno domínio do nível fonológico da língua, tanto no que diz respeito à combinação dos fonemas da língua quanto ao sistema silábico. Não há troca de fonemas e os padrões silábicos da língua são respeitados. 0 participante demonstra também dominar perfeitamente 0 sistema ortográfico da língua, desde o emprego das letras que representam graficamente os sons da língua até o uso das convenções da escrita, como emprego de maiúsculas e minúsculas. Quanto ao nível morfossintático, observa-se, inicialmente, coerência entre a resposta e a pergunta feita: 0 participante inicia o período com a conjunção "porque", retomando o que lhe foi perguntado. Há obediência à estrutura fundamental da oração em português (sujeito - verbo complemento) na construção do período. O participante demonstra pleno domínio da construção de período complexo com oração adjetiva, empregando adequadamente todos os elementos coesivos.

$O$ único problema que se identifica na resposta é a ausência de sinal de pontuação (dois pontos) para introduzir o tema mencionado ("as pesquisas dos cientistas"...)

3) 0 que o autor do texto está defendendo?
"Ele tem certeza de que a maioria dos leitores sabe responder as perguntas".
- 0 autor tem certeza que a maioria dos leitores sabem responder as perguntas.

O participante $\mathrm{M}$ demonstra pleno domínio do nível fonológico da língua, tanto no que diz respeito à combinação dos fonemas da língua quanto ao sistema silábico. Não há troca de fonemas e os padrões silábicos da língua são respeitados. 0 participante demonstra também dominar perfeitamente 0 sistema ortográfico da língua, desde o emprego das letras que representam graficamente os sons da língua até o uso das convenções da escrita, como emprego de maiúsculas e minúsculas. No nível morfossintático, há coerência com a pergunta: o participante retoma o sintagma "o autor do texto" por meio do pronome pessoal "ele". O período é coeso e coerente e encontra-se construído de acordo com as normas do português padrão. Ressalte-se a obediência à prescrição gramatical no que se refere à regência nominal ("tem certeza de") e à concordância verbal com o núcleo do sintagma nominal participante ("a maioria dos leitores sabe").

4) Você concorda com o autor? Por quê?

$\begin{array}{ll}\begin{array}{l}\text { "Sim. Concordei com o } \\ \text { autor sobre as perguntas". }\end{array} & \text { - Eu concordei com o autor. } \\ & \begin{array}{l}\text { Eu concordei com as per- } \\ \text { guntas. }\end{array}\end{array}$
guntas.
O participante $\mathrm{M}$ demonstra pleno domínio do nível fonológico da língua, tanto no que diz respeito à combinação dos fonemas da língua quanto ao sistema silábico. Não há troca de fonemas e os padrões silábicos da língua são respeitados. 0 participante demonstra também dominar perfeitamente 0 sistema ortográfico da língua, desde o emprego das letras que representam graficamente os sons da língua até o uso das convenções da escrita, como emprego de maiúsculas e minúsculas. Do ponto de vista morfossintático, a resposta mantém coerência com a pergunta. 0 período obedece às regras do português padrão quanto à regência e à pontuação. O participante deixou de observar o tempo verbal empregado na pergunta e respondeu empregando tempo verbal diferente (a pergunta está no presente e a resposta no passado). Observe-se tempo é uma noção semântica, que é marcada morfologicamente, no verbo, por meio de sufixo flexional. 


\begin{tabular}{lll}
\hline Perguntas & Respostas & Proposições \\
\hline 5) Escreva com suas & "Os planetas girarem em & - Os planetas giram. \\
palavras o que & torno do Sistema Solar. Os & - Os planetas giram em torno \\
você entendeu do & cientistas, antigamente, & do sistema solar. \\
texto. & pensam como funciona a & - Os cientistas pensam sobre o \\
& natureza da rotação dos & funcionamento da natureza. \\
& planetas". & - Os cientistas pensam sobre a \\
& & rotação dos planetas.
\end{tabular}

Análise gramatical

O participante $\mathrm{M}$ demonstra pleno domínio do nível fonológico da língua, tanto no que diz respeito à combinação dos fonemas da língua quanto ao sistema silábico. Não há troca de fonemas e os padrões silábicos da língua são respeitados. 0 participante demonstra também dominar perfeitamente 0 sistema ortográfico da língua, desde o emprego das letras que representam graficamente os sons da língua até o uso das convenções da escrita, como emprego de maiúsculas e minúsculas. Do ponto de vista fonológico, retome-se a análise feita na questão 1. Do ponto de vista morfossintático, a resposta está bem estruturada. A organização sintática é adequada, o princípio da concordância nominal e verbal foi respeitado, assim como a pontuação obedece às regras da escrita padrão. Há problema no emprego das formas verbais. O participante parece ter dificuldade em distinguir a noção de tempo/modo verbal. Emprega futuro do subjuntivo no lugar do presente do indicativo ("girarem" por giram) e emprega o presente em lugar do passado imperfeito ("pensam" no lugar de "pensavam"). Do ponto de vista semântico, verifica-se impropriedade no emprego do termo "sistema solar". Nesse caso, o participante parece não conseguir distinguir a parte do todo. $O$ participante parece ter dificuldade também no emprego de palavras abstratas, como "natureza", incorrendo em erro de incompatibilidade semântica ao combinar a palavra com a forma verbal "funciona". Ressalte-se, a esse respeito, a alta complexidade desse conhecimento. A consideração desse fato depende do grau de letramento do participante. Atente-se, ainda, que os dados são insuficientes para qualquer conclusão.

6) Você sentiu algu- "Sim. Senti maior dificulda- - Eu senti grande dificuldade 0 participante define que sua dificuldade está relacionada à ma dificuldade em relação ao texto? de de entender o vocabuláde entender vocábulos. compreensão de vocábulos e frases.

Qual dificuldade? "pesada".

- Eu senti que as frases são difíceis.

- Eu senti que as frases são pesadas.

7) Você sentiu dificuldade em entender e responder as perguntas? Por quê? Qual a dificuldade?
Sim. Porque o texto contém - Eu senti dificuldade porque 0 português é muito difícil para os surdos entenderem. Entendo pouco português. Costumo acompanhar com intérprete que pode ajudar a interpretar o que texto fala, traduz LIBRAS para os surdos podem entender melhor. Se os surdos já entenderem a interpretação de sinais sobre o que fala o texto. Surdos podem escrever suas próprias palavras, mais importante que os surdos entendem o texto. duzido para LIBRAS. texto tem português.

- Português é muito difícil para os surdos.

- Eu entendo pouco português.

- Eu acompanho o texto com intérprete.

- O intérprete pode ajudar.

- O intérprete interpreta o texto.

- O intérprete traduz o texto para LIBRAS.

- O surdo pode entender melhor quando o texto é tra-

- Os surdos podem escrever.

- Os surdos podem utilizar suas palavras quando escrevem.

- O mais importante é entender o texto.

- O mais importante é o surdo entender o texto.
O participante generaliza afirmando que a dificuldade do surdo com o português advém da limitação sensorial. Desta forma Acredita que todos os surdos inclusive ele tem dificuldade em dominar uma segunda língua. 0 participante defende a ação do tradutor intérprete para a compreensão textual. 
TABELA 2

Identificação das Competências e Dificuldades do Ponto de Vista da Produção Textual do Participante M

\begin{tabular}{|c|c|c|}
\hline $\begin{array}{l}\text { Elementos da produ- } \\
\text { ção textual }\end{array}$ & Competências & Dificuldades \\
\hline Sistema fonológico & $\begin{array}{l}\text { Sistema fonológico: combinações de fonemas e sistema silábico } \\
\text { Padrões silábicos. }\end{array}$ & \\
\hline Sistema ortográfico & $\begin{array}{l}\text { Representação gráfica dos sons da língua portuguesa. } \\
\text { Convenções da escrita. } \\
\text { Emprego de maiúsculas e minúsculas. } \\
\text { Regência e pontuação. }\end{array}$ & Pontuação (emprego dos "dois pontos") \\
\hline $\begin{array}{l}\text { Estrutura morfossin- } \\
\text { tática }\end{array}$ & $\begin{array}{l}\text { Emprego do morfema flexional de número, tanto no artigo quanto no substantivo. } \\
\text { Normas de produção frasal. } \\
\text { Coerência entre resposta dada e pergunta feita. } \\
\text { Emprego da conjunção "porque." } \\
\text { Há obediência à estrutura fundamental da oração em português (sujeito - verbo - } \\
\text { complemento) na construção do período. } \\
\text { Construção de período complexo com oração adjetiva. } \\
\text { Emprego do pronome pessoal "ele" para retomar o sintagma nominal. } \\
\text { Organização sintática adequada. } \\
\text { Concordância nominal e verbal. } \\
\text { Regência nominal } \\
\text { Concordância verbal: núcleo do sintagma nominal/sujeito. } \\
\text { Emprego do elemento de coesão (a conjunção aditiva "e") } \\
\text { Emprego da conjunção aditiva para ligar os sintagmas nominais. } \\
\text { Construção de período: coesão e coerência. }\end{array}$ & $\begin{array}{l}\text { Tempo verbal: pergunta } \neq \text { resposta } \\
\text { Emprego de formas verbais. } \\
\text { Noção de tempo/modo verbal. } \\
\text { Articulação: parte /todo. } \\
\text { Emprego de substantivos abstratos. }\end{array}$ \\
\hline
\end{tabular}

\section{RESULTADOS E DISCUSSÃO}

De acordo com os dados sistematizados nas tabelas, apresentamos os resultados sintetizando-os em referência a cada participante e discutindo-os. Embora as questões sobre as concepções dos participantes a respeito de suas competências e dificuldades tenham sido as últimas no protocolo, vindo após as questões sobre a compreensão do texto, optamos por iniciar por elas, uma vez que as mesmas explicitam a diferença entre tais concepções e a competência evidenciada nas suas respostas escritas às questões sobre a compreensão do texto que lhes foi proposto.

\section{Participante M}

M afirma ter tido dificuldade com a compreensão do texto explicitando que a surdez dificulta o domínio do conjunto lexical e da estruturação sintática da língua, e aponta o intérprete como meio de superação de tal dificuldade. Apesar disso, $\mathrm{M}$ demonstra ter compreendido o texto e ter escrito corretamente os vocábulos utilizados o que poderia caracterizar o domínio do sistema fonológico da língua portuguesa. Combina adequadamente os padrões alfabéticos o que transparece no emprego do sistema lexical. Respeita padrões e convenções empregando corretamente letras maiús- culas e minúsculas e a pontuação na construção das frases. Constrói períodos complexos com orações adjetivas, utiliza a estruturação canônica do português na construção das orações (sujeito, verbo, complemento) respeitando a coerência, a coesão textual e as normas da sintaxe, inclusive no que se refere à concordância nominal e verbal.

É bem verdade que, em algumas construções frasais, existem evidências de que o tempo verbal difere entre pergunta e resposta. O emprego de formas verbais bem como a articulação entre tempo e modo não são coerentes. O participante $\mathrm{M}$ apresenta dificuldade no emprego de substantivos abstratos representada por incompatibilidade semântica e incompreensão da relação parte/todo.

A coerência no emprego do padrão alfabético transparece na ortografia do conjunto lexical empregado pelo participante. Acreditamos, assim como Fernandes (1990), que a capacidade visual dos surdos pode justificar o seu bom desempenho na ortografia, uma vez que para Flaherty (2000) estes sujeitos utilizam propriedades visuais das letras e das palavras que caracteriza uma estreita relação entre memória visual e habilidades de escrita. Se isto é verdade, o ensino da escrita para os surdos baseado na oralização das pala- 
vras ou na valorização das codificações fonológicas torna-se inapropriado, mesmo porque, como defende Ferreiro (1987), Goodman (1987) e Mayer e Moskos (1998), a ortografia das palavras não necessariamente leva à aprendizagem da estrutura da leitura e escrita de uma língua oral.

O participante $\mathrm{M}$, ao demonstrar conhecer a estruturação canônica do português na construção das orações, respeitando a coerência, a coesão textual e as normas da sintaxe, inclusive no que se refere à concordância nominal e verbal, e ainda apresentar produção de períodos complexos e compreensão do texto lido, contraria a literatura na área. (cf. Góes, 1996; Lang \& Albertini, 2001; Luetlke-Stahlman \& Nielsen, 2003; Perfetti \& Sandak, 2000; entre outros).

Por outro lado, M, muito embora empregue adequadamente elementos de coesão e organização sintática adequada em algumas construções frasais, em outras apresenta inadequações ao empregar o tempo verbal que muitas vezes difere entre a questão proposta e a sua resposta evidenciando dificuldades também no emprego de formas verbais bem como na articulação entre tempo e modo. Os estudos de Góes (1996), por exemplo, apontam que tais características são peculiares à produção escrita dos surdos, o que para esta autora, se justifica, em grande parte, pelas regras da Língua Brasileira de Sinais.

No entanto, acreditamos que possivelmente o surdo tenha dificuldades em desenvolver a consciência morfossintática da língua oral devido ao processamento lingüístico utilizado por ele. Não estamos falando que o processamento viso-espacial seja uma estratégia cognitiva limitada, apenas estamos assinalando que este é um processo cognitivo particular. Além disso, é possível que tenha se desenvolvido uma esfera de dependência em que o surdo acredita ser incapaz de compreender um texto escrito em segunda língua sem a intervenção de um intérprete. Esse posicionamento nos parece algo aprendido ao longo das interações estabelecidas pelo surdo não somente em seu processo de escolarização, mas também, nas interações experenciadas nos diferentes contextos sociais.

\section{Participante R}

Semelhante a M, R justifica sua dificuldade em relação à compreensão do texto pela complexidade do sistema lexical, afirmando que o seu "português é meio fraco" o que prejudica a sua compreensão textual. O participante enfatiza a importância do intérprete deixando transparecer, uma certa insegurança, sobre a sua própria capacidade de compreensão textual.

No entanto, $\mathrm{R}$ apresenta domínio das construções lexicais; o que se traduz na combinação adequada de fonemas e padrões silábico-alfabéticos. Respeita as convenções da escrita empregando corretamente o uso de letras maiúsculas e minúsculas; emprega adequadamente abreviações e a pontuação, inclusive a vírgula. Constrói períodos complexos com orações de valor adjetivo observando o encadeamento do sistema flexional, concordância nominal e verbal além de apresentar encadeamento lógico de idéias empregando adequadamente algumas conjunções.

Por outro lado, é possível verificar na produção escrita do participante uma fragmentação do discurso, caracterizado pela construção de períodos típicos da oralidade com entrecortes e emprego de pronome em $1^{\text {a }}$ pessoa do singular; na variação de concordância, na construção sintática circular e na repetição de termos. Além desses aspectos, a produção escrita do participante apresenta repetição de estruturas oracionais e omissão de termos não obedecendo às regras da língua escrita padrão. O participante demonstra ter dificuldade no emprego do tempo verbal e na articulação sintática das frases omitindo o conector em sintagma nominal e preposicional, construindo períodos sem coesão.

O domínio do sistema ortográfico aparece novamente como aspecto comum à produção escrita de surdos. Tanto o participante $\mathrm{R}$ como o participante $\mathrm{M}$ apresentam, em suas produções, evidências de familiaridade com os padrões silábico-alfabéticos da língua portuguesa, com as convenções da escrita e com as irregularidades ortográficas.

É bem verdade que na produção escrita de R, é possível encontrar sentenças simples, repetitivas, incompletas e curtas com pouca variação estrutural, omissão de advérbios e de conjunções, emprego inadequado de pronomes, de artigos definidos, indefinidos e de verbos auxiliares. Apesar desses aspectos caracterizarem as construções atípicas que, por exemplo, Góes (1996) já havia descrito, por outro lado poderia estar sinalizando uma orientação discursiva diferenciada, como proposto por Marschark, Mouradian e Halas (1994). Em todo caso, R demonstrou ser capaz de coordenar inúmeros aspectos e estratégias para construir significados e interpretar o texto, muito embora, como já dissemos, não acredite nessa capacidade. 


\section{Participante C}

C apresenta uma visão otimista em relação ao texto, embora afirme ter tido dificuldades devido à sua complexidade e à falta do hábito de responder questões, o que pode significar que na sua história de escolarização a compreensão textual não tenha sido uma atividade freqüente. $\mathrm{O}$ participante apresenta bom domínio lexical, respeito aos padrões silábicos, combinações adequadas de fonemas e representação gráfica dos sons da língua portuguesa. Observa as convenções da escrita empregando corretamente a pontuação e letras maiúsculas e minúsculas. Constrói as orações baseadas nas regras da sintaxe com encadeamento lógico, nexo coesivo e articulação entre pergunta e resposta e emprega adequadamente a proposição "sobre” e as conjunções aditivas.

Por outro lado, algumas de suas respostas não apresentam coerência em relação ao enunciado da questão, o que pode ser indício de uma certa limitação quanto à compreensão do texto proposto. Algumas estruturas oracionais são construídas de forma incompleta apresentando agrupamento de palavras, tornando deficitária a comunicação na modalidade escrita. Existem evidências de que o $\mathrm{C}$ não domina a língua portuguesa escrita apresentando inversão na ordem canônica da estrutura oracional com inadequações gramaticais quanto ao emprego do complemento verbal e a coesão entre sujeito-verbo e verbo-complemento. Há indícios, portanto, de que $\mathrm{C}$ tem dificuldades em utilizar a língua portuguesa escrita como instrumento do pensamento.

Assim como os participantes anteriores, C apresenta domínio da ortografia do conjunto lexical empregado, o que reforça a justificativa de que o bom desempenho dos surdos na ortografia deve-se à sua capacidade de percepção visual, ao mesmo tempo em que corrobora nossa tese de que a aquisição do vocabulário em si, não garante, necessariamente, a competência lingüística no uso de uma segunda língua (ver estudos de Luetke-Stahlman \& Nielsen, 2003; Mayer \& Akamatsu, 2000; Perfetti \& Sandak, 2000).

\section{Participante MN}

MN aponta o sistema lexical da língua portuguesa como a fonte da sua dificuldade em relação ao texto proposto, afirmando ter tido dificuldade na compreensão do texto, enfatizando sua limitação em se expressar por meio da escrita e a falta de incentivo para a leitura, embora procure escrever corretamente. Apesar disto, MN estabelece coerência entre questão proposta e resposta escrita, obedece ao padrão gramatical do português, respeita a estruturação oracional e emprega corretamente elementos de coesão em períodos subordinados. Estes dados podem indicar que MN consegue identificar a estrutura da língua portuguesa e empregar o conjunto lexical internalizado de forma a conseguir estabelecer a comunicação, embora tenha dificuldades em ordenar elementos na estruturação das orações e coordenar as orações subordinadas.

Nas suas construções lexicais, MN respeita os padrões silábicos, faz uso de combinações adequadas de fonemas e representação gráfica dos sons da língua portuguesa, observa as convenções da escrita padrão empregando corretamente a pontuação e letras maiúsculas no início dos períodos, que são estruturados por subordinações sucessivas com seus respectivos elementos de coesão. MN emprega corretamente a preposição, os sintagmas nominais, o artigo e a conjunção aditiva nas estruturas oracionais além de elementos de coesão entre períodos. Apresenta facilidade na compreensão textual associando, na redação de suas respostas, conceitos abstratos e áreas particulares do conhecimento e empregando adequadamente os processos de nominalização, flexão verbal, concordância número/pessoal e o uso do gerúndio.

No entanto, a produção escrita de MN apresenta alternância quanto ao emprego de maiúsculas e minúsculas em relação à escrita de substantivos. Emprega formas ortográficas dissociadas da forma padrão da escrita da língua portuguesa, além de não empregar corretamente o ponto final e a vírgula em oração adjetiva e explicativa. Apresenta ainda, dificuldade em ordenar elementos na estruturação das orações e de coordenar as orações subordinadas. Na sua produção escrita, tomando como referência o sistema de escrita da língua portuguesa, é possível verificar que o participante utiliza, predominantemente, o presente do indicativo como tempo verbal, omite preposições e conjunções em algumas frases, emprega de forma inadequada o artigo definido, indefinido e alguns vocábulos.

Novamente os resultados evidenciam que o domínio do sistema ortográfico é um dado comum aos nossos participantes. Gaustad (2000), em uma revisão de literatura, cita autores como Tranler, Leybaert e Gombert (1999) e descreve que os surdos usuários da língua de sinais, utilizam padrões visuais tanto para soletrar como para ler as palavras.

A produção escrita dos nossos participantes até aqui, nos faz refletir sobre duas premissas defendidas 
na literatura - 1) o surdo, na leitura e escrita, utiliza codificações viso-espaciais e não correspondência grafonêmica (Capovilla, Capovilla \& Suiter, 2004; Gaustad, 2000; Flaherty \& Moran, 2004; Miller, 2006; Tractenberg, 2002; entre outros); 2) o surdo desenvolve sensibilidade fonológica em processos de leitura e escrita (Akamatsu, Sterwart \& Becker, 2000; Mayer \& Akamatsu, 2000; Perfetti \& Sandak, 2000; Sutcliffe, Dowker \& Campbell, 1999; entre outros).

Estas premissas são compatíveis com os estudos de Harris e Moreno (2004), que evidenciam que os surdos são sensíveis a modificações da ordem das letras na palavra e, ao contrário dos seus pares ouvintes, dificilmente se enganam com as irregularidades fonológicas e grafológicas. Os resultados obtidos por esses autores caracterizam o processamento viso-espacial dos surdos na codificação das palavras, o que pode explicar o bom desempenho desses participantes no domínio do sistema ortográfico e possivelmente justifica o bom desempenho dos nossos participantes em relação à ortografia.

Assim, acreditamos que o participante $\mathrm{MN}$, possivelmente, tenha construído a sua escrita utilizando estratégias visuais, e não os recursos fonológicos. Se isto é verdade, o participante, então, utiliza a própria língua de sinais como base de suas construções em segunda língua como sugerem Góes (1996) e Harris e Moreno (2004), o que pode justificar a desarticulação de elementos e o emprego de vocábulos sem coesão entre si. Segundo estes autores, os surdos tendem a usar estratégias da sua própria língua para escrever alternando, em suas produções escritas, ora a estrutura do português ora a estrutura da LIBRAS. Por isso mesmo, as omissões de termos correspondem, em grande parte, aos aspectos da mensagem que não são expressas na língua de sinais (cf. Marschark, Mouradian \& Halas, 1994).

\section{Participante CA}

CA afirma ter tido dificuldades em relação ao texto proposto por uma limitação lingüística. Segundo CA o português é um mundo "estranho" onde as palavras muitas vezes não são compreendidas. O participante acredita que o surdo tem uma linguagem diferente e que por esse motivo as palavras em português são difíceis chegando a ser, muitas vezes, uma grande barreira que o participante caracteriza como "inimigo”. Para CA, a LIBRAS é uma língua que deve ser valorizada e o recurso que ajuda o surdo a entender o português e a compreender o texto em questão. A presença de um profissional intérprete é apontada, novamente, como um recurso importante. Para CA esse profissional traduziria as palavras do português para a LIBRAS, facilitando o entendimento e a compreensão textual.

Apesar disso, CA apresenta um bom domínio do sistema lexical da língua, respeita os padrões silábicos, faz uso de combinações adequadas de fonemas, apresenta domínio da ortografia observando as convenções da escrita padrão das palavras, porém, emprega aleatoriamente letras maiúsculas e minúsculas. A pontuação não segue as normas canônicas. Nas respostas dadas pelo participante não há uma relação lógica entre os termos da sintaxe. O período torna-se agramatical sem coerência devido ao emprego inadequado de elementos coesivos e à predominância de substantivos enumerados, o que não condiz à estrutura oracional da língua portuguesa e conseqüentemente o que torna limitada a expressão do pensamento por meio da escrita. Não há nexo coesivo entre as orações subordinadas e entre o núcleo e o substantivo de tais orações. Não há coesão entre as orações e nem coerência entre pergunta feita e resposta dada. A flexão verbal é inapropriada, existem omissões, não há coerência entre pessoa/tempo/modo e alguns verbos são empregados incorretamente no infinitivo e no início da oração. Não há concordância de gênero e emprego adequado de artigos.

Notamos que do ponto de vista da ortografia, a produção escrita do participante CA é exemplo de que o surdo desenvolve a codificação viso-espacial das palavras e que transpor a mensagem para a estrutura do português padrão não é algo trivial. Não obstante da análise de que este participante poderia estar desenvolvendo justaposição de línguas, o português e a LIBRAS como defende Góes (1996), acreditamos que CA possivelmente esteja utilizando a estrutura da sua própria língua em sua produção escrita.

$\mathrm{Na}$ análise gramatical, tendo por base as proposições extraídas das respostas do participante, fica evidenciado que CA não domina o sistema da língua portuguesa e estamos falando de algo mais complexo do que as regras de escrita de uma língua. CA comete erros que o falante nativo da língua portuguesa jamais cometeria como, por exemplo, antecipar o verbo principal da locução. Desta forma, a análise gramatical aponta como conclusão que CA deve utilizar um outro sistema lingüístico, que não o português, para se comunicar.

A literatura na área da surdez tem relatado resultados semelhantes a estes. É comum encontrarmos auto- 
res que afirmam que o surdo, usuário de língua de sinais, diante de um texto, seja complexo ou não, utiliza estratégias da sua própria língua para ler e escrever (cf. Harris \& Moreno, 2004). Para os autores, a prova disso é o impacto significativo do implante coclear no desenvolvimento da leitura e escrita. Crianças surdas implantadas, em menos de um ano já conseguem apresentar desenvolvimento satisfatório na leitura o que significa que estas crianças começaram a fazer uso dos princípios lingüísticos do sistema alfabético.

As disfunções encontradas na produção do participante CA, como os termos da sintaxe sem relação lógica, emprego inadequado de elementos coesivos, predomínio de substantivos na construção frasal entre outros aspectos, não se distanciam das análises feitas nos trabalhos de Marschark, Mouradian e Halas (1994). Nas construções frasais de CA fica evidente a omissão de termos, que como já mencionamos, podem ser analisadas por dois caminhos, ou elas correspondem aos aspectos da mensagem que não são expressas em língua de sinais ou o participante desenvolveu uma orientação discursiva inapropriada. Esta última hipótese está estreitamente relacionada com a prática pedagógica e mais especificamente com as mediações de aprendizagem que este participante experimentou ao longo do seu processo de escolarização.

Para Marschark, Mouradian e Halas. (1994) o ensino da escrita para o surdo é descontextualizado e em geral é feito por um processo enfadonho de memorização de palavras e sentenças, o que pode justificar as caracterizações da escrita do surdo apontadas na literatura da área. Podemos, no entanto, fazer um outro raciocínio. Os problemas na estrutura discursiva na escrita do surdo, pode ser devido à não-aquisição de padrões de conversação típicos das interações verbais o que levaria a uma transposição de língua de forma não convencional. Isso nos permite dizer que a criança ouvinte em suas produções recorre às estruturas discursivas fonológicas e a criança surda não.

\section{Participante S}

$\mathrm{S}$ afirma ter tido alguma dificuldade na compreensão textual. Aponta os vocábulos como fonte de tal dificuldade acrescentando que estes são complexos e difíceis para os surdos. O participante enfatiza que leu o texto várias vezes para que pudesse entendê-lo melhor pulando as palavras difíceis o que, segundo o participante, compromete a compreensão de algumas partes do texto. S admite não entender o texto da mesma forma que um ouvinte acreditando que este tem maior facilidade para entendê-lo. Acrescenta que para responder adequadamente às perguntas propostas é necessária a compreensão textual, uma vez que segundo S, as respostas são argumentações e evidenciam a própria compreensão do texto.

Embora o participante tenha demonstrado ser lingüisticamente competente, afirma ter tido dificuldade na compreensão textual justificando tal dificuldade pela complexidade dos vocábulos. S acredita que todos os surdos têm dificuldade com o português devido à complexidade do vocabulário e que isto prejudica o seu domínio tornando-o insuficiente para a proficiência na língua. $\mathrm{O}$ nosso participante acrescenta que o ouvinte tem maior facilidade para a compreensão textual não fazendo referência à hipótese explicativa para tal condição. Notamos que o discurso do nosso participante pode ser resumido em duas proposições: 1) o sistema lexical da língua portuguesa é complexo para o surdo; 2) o ouvinte tem mais facilidade para a compreensão textual do que o surdo.

Podemos dizer que o participante não chegou a estas proposições sozinho. Como diz Fávero (2005), as ações humanas não são aleatórias, ao contrário, são construídas nas interações que o participante estabelece ao longo do seu desenvolvimento e, portanto, provavelmente o participante não só aprendeu que tem dificuldades na compreensão textual como também a se comportar diante do texto dessa forma; como aquele que tem dificuldades de compreensão textual.

Embora o participante S apresente em suas produções escritas inadequações no emprego de alguns termos da sintaxe, como, por exemplo, preposições, adjetivos e elementos de coesão, não empregando adequadamente tais termos ou omitindo alguns deles em suas construções frasais, não necessariamente isso quer dizer que o participante desconheça os termos e seus significados. O fato de não posicioná-los conforme as convenções da escrita da língua portuguesa pode indicar, como já mencionamos, que o participante esteja utilizando por base a sua língua materna no processo de escrita (cf. Marschark, Mouradian \& Halas, 1994), ou que o participante ainda não conseguiu articular os princípios lingüísticos da língua alvo.

Apesar disso, S demonstra competência lingüística do ponto de vista da estrutura ortográfica evidenciando um bom domínio lexical. Respeita os padrões silábicos, faz uso de combinações adequadas de fonemas, observa as convenções da escrita padrão empregando corretamente a pontuação. A estrutura oracional segue 
o padrão gramatical do português evidenciando coerência entre as perguntas feitas e as respostas dadas. Desenvolve períodos complexos com relações coesivas, formulações analíticas e processos precisos de nominalização.

A estruturação sintática é apropriada e coerente às regras canônicas da língua portuguesa. Os períodos têm encadeamentos lógicos, são coesos e coerentes respeitando o emprego dos elementos de coesão e as regras da concordância nominal e verbal. Apresenta domínio lexical, emprego preciso dos vocábulos e facilidade na elaboração de respostas e na compreensão textual. S apresenta, porém, inadequações no emprego de letras maiúsculas e minúsculas no início dos períodos e em nomes próprios. Demonstra dificuldade no emprego de preposições, adjetivos, elementos de coesão "que" e "dentre", e no emprego do pronome demonstrativo "esses".

Há de se considerar que a transposição da mensagem para o português pode ser um desafio para o surdo pela questão da natureza da codificação utilizada por ele. Este participante desenvolve estratégias cognitivas diferenciadas, daquelas dos ouvintes, para acessar o sistema lingüístico alfabético quando em processo de aquisição da língua escrita.

\section{CONCLUSÃO}

Iniciamos este estudo com a questão de como favorecer o desenvolvimento da consciência sintática e morfossintática da língua escrita no surdo e de como mediar as diferentes áreas do conhecimento tomando por base o processamento viso-espacial. Evidenciamos que o surdo elabora hipóteses de escrita da mesma forma que o ouvinte e que as chamadas irregularidades da produção escrita dos surdos, são irregularidades porque se toma como critério, a estrutura da língua oral, desconsiderando que a língua materna destes sujeitos possui sua própria lógica de estruturação.

Entendemos que esta lógica não deve ser negligenciada e, muito menos, desvalorizada a partir de uma outra estrutura lingüística. Assim, a nossa hipótese de que as referidas construções atípicas na produção escrita do surdo são frutos de uma prática de alfabetização, se sustenta. Ainda hoje, o status da língua de sinais como instrumento semiótico é negligenciado. As crianças, adolescentes e adultos surdos, experimentam em sua escolarização um processo similar de alfabetização àquele utilizado junto aos sujeitos ouvintes, cuja língua materna é o português. E para agravar a situação, assim como assinalam Quadros
(2004) e Quadros e Karnopp (2004), os professores tendem a mediar o ensino da língua portuguesa, tanto para surdos quanto para ouvintes, por meio de regras do próprio sistema lingüístico, explicando a língua pela língua, ignorando o seu processo de construção dialógica.

Gesueli e Moura (2006), buscando um novo olhar sobre a escrita de surdos, defendem que este sujeito, uma vez que utiliza os aspectos visuais da sua língua materna no processo de aquisição de uma segunda língua, deveria experimentar na escola mais de um código semiótico no seu processo de letramento. As autoras acrescentam que, o letramento destes sujeitos, deve ser visual e contar com o apoio dos recursos tecnológicos disponíveis. Silva (1999) aponta caminhos para a re-significação do trabalho pedagógico realizado junto a surdos, defendendo que estes sujeitos são capazes de produzir um texto em segunda língua com sentido, e para isso sinaliza que a presença de um intérprete em LIBRAS facilita a interlocução entre as áreas do conhecimento.

Em todo caso, o discurso insistente de nossos participantes salientando suas dificuldades reflete uma política de educação de surdos traçada com base nessa bipolaridade, de um lado o não reconhecimento do status lingüístico da LIBRAS e do outro uma prática pedagógica inadequada ao ensino de segunda língua para o surdo, o que endossa, por sua vez, o discurso da limitação estrutural da língua de sinais, quando, ao contrário, se deveria remeter ao discurso da semiótica para dar sustentação à análise de ambas as estruturas a da língua oral e a da língua de sinais - procurando entender como tais estruturas podem se articular.

Ou seja: há que se conscientizar que a produção escrita dos surdos não é construída por meio da consciência fonológica o que particularmente, implica a utilização de diferentes estratégias cognitivas no processo de aquisição de uma segunda língua. Portanto, podemos dizer que dois aspectos são fundamentais para a questão que nos colocamos: 1) o português como segunda língua para o surdo deve ter uma metodologia diferenciada de ensino daquele desenvolvido com ouvinte que dispõe do português como língua materna; 2) deve-se levar em consideração que o surdo utiliza, no seu processo de leitura e escrita, o processamento visual e não as correspondências grafonêmicas.

Considerar estas duas questões implica, por sua vez, retomar a função sociocomunicativa do texto escrito, e rever o próprio conceito de texto, como su- 
gerido por Lotman (1991, citado por Fávero, 2005), tanto no que se refere à compreensão textual, como no que se refere à sua produção. Isto significa considerar a "articulação dos aspectos subjetivos, desenvolvimentais e cognitivos dos processos semióticos num contexto psicológico com o fundamento histórico, institucional e ideológico dos sistemas de signos num contexto sociocultural” (Fávero, 2005, p. 17).

Como proposto por Fávero e De Lima (1989) e De Lima e Fávero (1998) isto requer, do ponto de vista teórico e conceitual, considerar, ao mesmo tempo, a tipologia do texto, conforme proposta por Luria (citado por Scinto, 1983) e a semiótica de Lotman (1988a e 1988b), que elabora a proposição dos sistemas simbólicos como subtextos no texto mais amplo da cultura, o que significa, do ponto de vista psicopedagógico, trabalhar com significantes lidos e escritos, levando o sujeito a se engajar num processo de reflexão que crie instrumentos internos de amplificação e organização de informações, de modo que ele se comunique com o texto escrito e consigo mesmo, ampliando sua interação com o universo das representações letradas.

Estamos, portanto defendendo que é possível se desenvolver uma prática psicopedagógica de letramento junto ao surdo, que considere os dois aspectos referidos acima - o português como segunda língua e o processamento visual na leitura e escrita - e, ao mesmo tempo, a interação do surdo, seja criança, adolescente ou adulto, com os instrumentos de representação do conhecimento humano já convencionados. Desta forma, o desenvolvimento da consciência sintática e morfossintática não ficará no âmbito da utopia pedagógica.

Para tanto, sugerimos a proposta de Fávero (2003), que defende a importância de se centrar as investigações sobre a aquisição dos conceitos, tendo por método de investigação, o próprio procedimento de intervenção psicopedagógica, o que significa considerar a atividade mediada. Para esta autora,

(...) isto requer três tarefas distintas e articuladas: avaliação das competências do sujeito e de suas dificuldades; sistematização de cada uma das sessões de trabalho, em termos de objetivos e descrição das atividades propostas; análise minuciosa do desenvolvimento das atividades para cada sessão, explicitando: a seqüência de ações do sujeito; o significado destas ações em relação às suas aquisições de estruturas conceituais; o tipo de mediação estabelecida entre o adulto e o sujeito. Metodologicamente esta proposta pressupõe: que a intervenção seja planejada segundo uma avaliação das competências conceituais do su- jeito e não no seu treino para responder a tarefas escolares; que cada sessão de intervenção seja planejada de acordo com os dados obtidos na anterior. (p. 83)

Trata-se, portanto, da proposta de um trabalho sistematizado de articulação entre intervenção e pesquisa, que permite o estudo das aquisições conceituais por meio da produção do sujeito, considerando-se a filiação entre competências e dificuldades, o que permite situar todo caso individual e, ao mesmo tempo, a análise dos processos mediacionais ocorridos na interação interpessoal, o que inclui o tipo de material utilizado e a natureza das atividades propostas (Fávero, 2003, p. 83).

Desenvolver um estudo de caso segundo tal proposta será nosso próximo desafio.

\section{REFERÊNCIAS}

Akamatsu, T., Sterwart, D. A., \& Becker, B. J. (2000). Documenting english syntactic development in face-to-face signed communication. American Annals of the Deaf, 145(5), 452463.

Capovilla, A. G. S., Capovilla, F. C., \& Suiter, I. (2004). Processamento cognitivo em crianças com e sem dificuldades de leitura. Psicologia em Estudo, 9(3), 449-458.

Cline, T. (1997). Educating for bilingualism in different contexts: Teaching the deaf and teaching children with english as an additional language. Educational Review, 49(2), 151-158.

De Lima, S. G., \& Fávero, M. H. (1998). Learning to write letters: Semiotic mediation in literacy accquisition in adulthood. Em M. Kohl de Oliverira, \& J. Valsiner (Orgs.), Literacy in human development (p. 247-279). Stanford, CT: Ablex Publishing Corporation.

Evans, C. J. (2004). Literacy development in deaf students: Case studies in bilingual teaching and learning. American Annals of the Deaf, 149(1), 17-27.

Fávero, M. H. (2003). Aquisição conceitual em condições especiais: Articulação entre pesquisa e intervenção psicopedagógica. Em Sociedade Brasileira de Psicologia (Org.), Anais da XXXIII Reunião Anual de Psicologia (p. 83-84). Belo Horizonte: SBP.

Fávero, M. H. (2005). Desenvolvimento psicológico, mediação semiótica e representações sociais: Por uma articulação teórico metodológica. Psicologia: Teoria e Pesquisa, 21(1), 17-26.

Fávero, M. H., \& De Lima, S. G. (1989). A produção de texto por um migrante da zona rural: Um estudo de caso. Em Sociedade Brasileira de Psicologia (Org.), Anais da XIX Reunião Anual de Psicologia (p. 208). Ribeirão Preto: SBP.

Fávero, M. H., \& Trajano. A. A. A. (1998). A leitura do adolescente: Mediação semiótica e compreensão textual. Psicologia: Teoria e Pesquisa, 14(3), 229-240.

Fávero, M. H., \& Soares, M. T. C. (2002). Iniciação escolar e a notação numérica: Uma questão para o estudo do desenvolvimento adulto. Psicologia: Teoria e Pesquisa, 18(1), 43-50.

Fávero, M. H., \& Pimenta, M. L. (2006). Pensamento e linguagem: A língua de sinais na resolução de problemas. Psicologia: Reflexão e Crítica, 19(2), 60-71. 
Ferreiro, E. (1987). Processos construtivos de apropriação da escrita. Em E. Ferreiro \& M. G. Palácio (Orgs.), Os processos de leitura e escrita (p. 102-121). Porto Alegre: Artes Médicas.

Flaherty, M. (2000). Memory in the deaf: A cross-cultural study in English and Japanese. American Annals of the Deaf, 145(3), 237-244.

Flaherty, M., \& Moran, A. (2004). Deaf signers who know Japanese remember words and numbers more effectively than deaf signers who know English. American Annals of the Deaf, 149(1), 39-45.

Felipe, T. A. (1997). Introdução à gramática da LIBRAS. Série Atualidades Pedagógicas, 4(3), 81-107.

Fernandes, E. (1990). Problemas lingüísticos e cognitivos do surdo. Rio de Janeiro: Agir.

Ferreira-Brito, L. (1997). Língua Brasileira de Sinais - LIBRAS. Série Atualidades Pedagógicas, 4(3), 19-61.

Gaustad, M. G. (2000). Morphographic analysis as a word identification strategy for deaf readers. Journal of Deaf Studies and Deaf Education, 5(1), 60-80.

Gesueli, Z. M. (1988). A criança não ouvinte e a aquisição da escrita. Dissertação de mestrado não-publicada, Universidade Estadual de Campinas.

Gesueli, Z. M., \& Moura, L. (2006). Letramento e surdez: A visualização das palavras. Educação Temática Digital, 7(2), 110122.

Góes, M. C. R. (1996). Linguagem, surdez e educação. Campinas: Autores Associados.

Goodman, K. S. (1987). O processo de leitura: Considerações a respeito das línguas e do desenvolvimento. Em E. Ferreiro \& M. G. Palácio (Orgs.), Os processos de leitura e escrita (p. 1122). Porto Alegre: Artes Médicas.

Harris, M., \& Moreno, C. (2004). Deaf children's use of phonological coding: Evidence from reading, spelling, and working memory. Journal of Deaf Studies and Deaf Education, 9(3), 253-268.

Lang, H. G., \& Albertini, J. A. (2001). Construction of meaning in the authentic science writing of deaf students. Journal of Deaf Studies and Deaf Education, 6(4), 258-284.

Lotman, Y. M. (1988a). The semiotics of culture and the concept of a text. Soviety Psychology, 26(3), 52-58.

Lotman, Y. M. (1988b). Text within a text. Soviety Psychology, 26(3), 32-51.

Luetke-Stahlman, B., \& Nielsen, D. C. (2003). The contribution of phonological awareness and receptive and expressive English to reading ability of deaf students with varying degrees of exposure to accurate English. Journal of Deaf Studies and Deaf Education, 8(4), 464-484.

Madalena, P. S. (1997). A criança surda e a construção do conceito de número. Brasília: CORDE.

Marschark, M., Mouradian, V., \& Halas, M. (1994). Discourse rules in the language productions of deaf and hearing children. Journal of Experimental Child Psychology, 57, 89-107.
Mayer, C., \& Akamatsu, C. T. (2000). Deaf children creating written texts: Contributions of American sign language. American Annals of the Deaf, 145(5), 394-401.

Mayer, C., \& Moskos. E. (1998). Deaf children learning to spell. Research in the Teaching of English, 33(2), 158-180.

Meireles, E. S., \& Correa, J. (2005). Regras contextuais e morfossintáticas na aquisição da ortografia da língua portuguesa por crianças. Psicologia: Teoria e Pesquisa, 21(1), 17-26.

Meirelles, V., \& Spinillo, A. G. (2004). Uma análise da coesão textual e da estrutura narrativa em textos escritos por adolescentes surdos. Estudos de Psicologia, 9(1), 131-144.

Peixoto, C. R. (2006). Algumas considerações sobre a interface entre a língua brasileira de sinais (LIBRAS) e a língua portuguesa na construção inicial da escrita pela criança surda. $\mathrm{Ca}$ dernos Cedes, 26(69), 205-229.

Quadros, R. M. (1997). Educação de surdos: A aquisição da linguagem. Porto Alegre: Artes Médicas.

Quadros, R. M. (2004). Educação de surdos: Efeitos de modalidade e práticas pedagógicas. Em E. G. Mendes, M. A. Almeida \& L. C. A. Williams (Orgs.), Temas em educação especial: Avanços recentes (p. 55-61). São Carlos: UFSCar.

Quadros, R. M., \& Karnopp, L. B. (2004). Língua de sinais brasileira: Estudos lingüísticos. Porto Alegre: ArtMed.

Rinaldi, G. (1997). Deficiência auditiva I. Brasília: SEESP.

Scinto, L. F. M. (1986). Text, schooling, and the growth of mind. Em E. Mertz \& R. J. Parmentier (Orgs.), Semiotic mediation: Sociocultural and psychological perspectives (p. 203-218). Orlando, FL: Academic Press.

Silva, M. P. M. (1999). A construção de sentidos na escrita do sujeito surdo. Dissertação de mestrado não-publicada, Universidade Estadual de Campinas.

Singleton, J. L., Supalla, S., Litchfied, S., \& Schley, S. (1998). From sign to word: Considering modality constraints in ASL/English bilingual education. Academic Research Library, 18(4), 16-29.

Skliar, C. (1998). Bilingüismo e biculturalismo: Uma análise sobre as narrativas tradicionais na educação de surdos. Revista Brasileira de Educação, 8, 44-56.

Sutcliffe, A., Dowker, A., \& Campbell, R. (1999). Deaf children's spelling: Does it show sensitivity to phonology?. Journal of Deaf Studies and Education, 4(2), 111-123.

Virole, B. (2000). La pensée visualle. Em B. Virole (Org.), Psychologie de la surdité (p. 201-218). Bruxelles: De Boeck \& Lacier.

Zaitseva, G., Pursglove, M., \& Gregory, S. (1999). Vygotsky, sign language, and the education of deaf pupils. Journal of Deaf Studies and Deaf Education, 4(1), 9-15.

Recebido: 10/11/2006 Revisado: 31/05/2007 Aceito: 09/06/2007 


\section{ANEXO A: O TEXTO \\ Três Visionários Cósmicos}

Para uma pessoa vivendo no século 21, o fato de o sol ser o centro do sistema solar e de a Terra e os outros planetas girarem é tão conhecido que é considerado óbvio. Porém, se perguntarmos como é que sabemos disso as coisas começam a ficar menos óbvias. Afinal o que vemos da superfície da Terra é o céu girando à nossa volta e não vice-versa: é o sol que nasce no leste e se põe no oeste todos os dias, são as estrelas que parecem girar nos céus com o passar da noite, o mesmo ocorrendo com os planetas.

Mais ainda, como podemos afirmar que a Terra gira em torno do seu eixo, se não sentimos sua rotação? Por que ninguém fica tonto com ela?

Tenho certeza que a maioria dos leitores sabe responder a essas perguntas. Na Grécia antiga as coisas eram muito diferentes. Em torno de 600 a.C., quando os primeiros filósofos ocidentais começaram a explicar o funcionamento da natureza com argumentos racionais e não ações divinas, não havia razão para acreditar que a Terra estivesse em movimento. Aliás, esse é um excelente exemplo de como as aparências enganam.

Cerca de 150 anos se passaram até que alguém propusesse que a Terra não era imóvel, mas que girava em torno do centro do cosmo, juntamente com os demais planetas, a lua e as estrelas. O interessante dessa idéia proposta por Filolau de Cretona em torno de 450 a.C., é que o centro do cosmo não seria ocupado pelo sol, mas pelo "fogo central”, uma espécie de fornalha cósmica onde se originava todo o calor e toda a luz.

O sol que também girava em torno desse centro, simplesmente redistribuía a energia do fogo central pelo resto do cosmo. Filolau era seguidor das idéias do legendário Pitágoras, que havia fundado uma tradição místico-racional baseada na adoração dos números e de sua capacidade de descrever a beleza e a harmonia do mundo natural.

Algumas fontes atribuem a Pitágoras a suposição de que a Terra era esférica. Suas idéias, combinando geometria e aritmética na descrição da natureza, influenciaram um dos maiores cientistas da história, de Platão a Kepler e mesmo Einstein.

Aparentemente, Filolau propôs o movimento da Terra para explicar a rotação diurna dos céus: em vez de todos os planetas girarem em torno da Terra, ele propôs que a Terra giraria em torno do fogo central. Essa rotação teria o mesmo efeito que percebemos ao girarmos em um carrossel: o mundo gira em sentido contrário.

Claro, teria sido mais fácil supor que a Terra gira em torno de si própria, mas isso não correspondia à inspiração mística de Filolau, segundo o qual o centro do cosmo era a morada de Zeus, a fonte de toda a luz.

Cerca de cem anos depois de Filolau, outro pensador grego, Heráclides do Ponto, deu o pulo do gato: ele propôs que a rotação diurna dos céus resultaria da rotação da Terra em torno de si mesma. Heráclides propôs um cosmo híbrido, com o sol e outros planetas (na época Marte, Júpiter e Saturno) girando em torno da Terra, mas não Mercúrio e Vênus.

Contemporâneo de Aristóteles, Heráclides não foi levado a sério. Segundo Aristóteles, a Terra deveria ser o centro imóvel do cosmo. Afinal diria ele, como podemos provar que a Terra gira se, quando atiramos uma pedra para cima ela retorna às nossas mãos? Se a Terra girasse, seríamos carregados pela sua rotação, e a pedra cairia atrás de nós. Não se conhecia então o conceito de inércia que diz que algo que está em movimento tende a permanecer em movimento. A pedra quando atirada para cima tem também um movimento horizontal, causado pela rotação da Terra, tal como nós.

O último dos visionários que menciono hoje é Aristarco de Samos, o homem que em 300 a.C., pôs o Sol no centro do cosmos, com a Terra e os outros planetas girando à sua volta. Usando geometria, Aristarco provou que a Lua era bem menor do que a Terra, e a Terra bem menor do que o Sol. Portanto, concluiu, seria muito mais natural que o Sol estivesse no centro. Mais uma vez predominaram as idéias aristoléticas e Aristarco foi esquecido. Pelo menos até o século 16, quando o polonês Nicolau Copérnico, ciente das idéias de Aristarco pôs, de volta, o Sol no centro. 


\section{ANEXO B: O PROTOCOLO}

\section{Dados pessoais}

Nome:

Data de Nascimento:

Grau de surdez:

Ouvido direito: leve ( ) Moderada ( ) Severa ( ) Profunda ( )

Ouvido esquerdo: leve ( ) Moderada ( ) Severa ( ) Profunda ( )

\section{Escolaridade}

a) Se você já terminou o curso superior, responda:

Qual o curso que você fez?

Em que ano terminou?

\section{b) Se você ainda não terminou o curso superior, responda:}

Qual o curso que está fazendo?

Qual o semestre que está cursando?

\section{Compreensão textual}

Leia as questões abaixo e responda de acordo com o seu entendimento. Lembre-se que isto não é uma avaliação do seu conhecimento em português, mas um trabalho voluntário de pesquisa.

Obrigada!

1) Qual o assunto tratado no texto?

2) Na sua opinião, por que o autor nomeou o texto de três visionários cósmicos?

3) O que o autor do texto está defendendo?

4) Você concorda com o autor? Por quê?

5) Escreva com suas palavras o que você entendeu do texto.

6) Você sentiu alguma dificuldade em relação ao texto? Qual a dificuldade?

7) Você sentiu dificuldade em entender e responder as perguntas? Por quê? Qual a dificuldade?

\section{Nota:}

${ }^{1}$ Este estudo foi desenvolvido no âmbito do Projeto de Pesquisa - A construção de competências na escola- CNPq, proc. 305 305/2004-4 - coordenado pela primeira autora.

\section{Sobre as autoras:}

Maria Helena Fávero: Professora orientadora do Programa de Pós-Graduação do Instituto de Psicologia da Universidade de Brasília Meireluce Leite Pimenta: Professora da Secretaria do Estado de Educação, Brasília, DF; Mestre em Psicologia e Doutoranda do Programa de Pós-Graduação do Instituto de Psicologia da Universidade de Brasília

Márcia Rangel Pacifici: Professora da Secretaria do Estado de Educação, Brasília, DF; Mestre em Lingüística pela Universidade de Brasília

Endereço para correspondência: Maria Helena Fávero - SQN 205 - Bloco L - apto. 506 - CEP 70843-120 - Brasília/DF - Fone: (61) 3478661 - Endereço eletrônico: faveromh@unb.br 